NASA Technical Memorandum 105413

AIAA - 92-2348

\title{
Reliability Analysis of Laminated CMC Components Through Shell Subelement Techniques
}

\author{
Alois Starlinger \\ Lewis Research Center \\ Cleveland, Ohio \\ Stephen F. Duffy \\ Cleveland State University \\ Cleveland, Ohio \\ and \\ John P. Gyekenyesi \\ Lewis Research Center \\ Cleveland, Ohio
}

Prepared for the

33rd Structures, Structural Dynamics and Materials Conference

sponsored by the American Institute of Aeronautics and Astronautics

Dallas, Texas, April 13-15, 1992 


\title{
RELIABILITY ANALYSIS OF LAMINATED CMC COMPONENTS
}

\section{THROUGH SHELL SUBELEMENT TECHNIQUES}

\author{
A. Starlinger \\ National Aeronautics and Space Administration \\ Lewis Research Center \\ Cleveland, Ohio 44135 \\ S.F. Duffy ${ }^{* *}$ \\ Department of Civil Engineering \\ Cleveland State University \\ Cleveland, Ohio 44115 \\ J.P. Gyekenyesi \\ National Aeronautics and Space Administration \\ Lewis Research Center \\ Cleveland, Ohio 44135
}

\begin{abstract}
$\underline{\text { Abstract }}$
An updated version of the integrated design program C/CARES (composite ceramics analysis and reliability evaluation of structures) was developed for the reliability evaluation of CMC laminated shell components. The algorithm is now split into two modules: a finite-element data interface program and a reliability evaluation algorithm. More flexibility is achieved, allowing for easy implementation with various finite-element programs. The interface program creates a neutral data base which is then read by the reliability module. This neutral data base concept allows easy data transfer between different computer systems. The new interface program from the finite-element code MARC also includes the option of using hybrid laminates (a combination of plies of different materials or different layups) and allows for variations in temperature fields throughout the component. In the current version of C/CARES, a subelement technique was implemented, enabling stress gradients within an element to be taken into account. The noninteractive reliability function is now

\footnotetext{
*National Research Council-NASA Research Associate at Lewis Research Center.

** NASA Resident Research Associate at Lewis Research Center.
}

evaluated at each Gaussian integration point instead of using averaging techniques. As a result of the increased number of stress evaluation points, considerable improvements in the accuracy of reliability analyses have been realized.

\section{$\underline{\text { Introduction }}$}

The development of propulsion systems for space vehicles as well as for hypersonic airplanes requires the use of engineered materials such as laminated ceramic matrix composites (CMC's). CMC material systems have low density and the advantage of maintaining strength at high temperatures, thus the demand for them in the design of high-temperature sections of aerospace structures. This demand requires focused research with specific attention paid to their inherent brittleness and variability in strength. Thus, analyses of components fabricated from ceramic materials require a departure from the usual deterministic design philosophy (i.e., the safety factor approach) prevalent in analyzing metallic structural components. Adopting the probabilistic approach outlined herein allows the design engineer to account for variability in strength and decreasing bulk strength with increasing component size. 
As in any structural analysis of a component, the stress field must be characterized. Commercial finite-element programs (e.g., MSC/NASTRAN, MARC, ABAQUS, ANSYS, etc.) exist and have laminate analysis capabilities which allow the design engineer to determine the structural response of composite components subjected to thermomechanical loads. Coupling these finite-element programs to an integrated probabilistic composite design program that evaluates the structural reliability is an attractive analytical tool in component design. Based on the preliminary version of the test-bed computer program C/CARES (composite ceramics analysis and reliability evaluation of structures), ${ }^{1}$ which was coupled to MSC/NASTRAN laminate analyses, a next-generation algorithm was developed. Thus, access to additional finite-element programs is allowed through the use of a formatted neutral data base. In the current version, a subelement technique has been implemented. The reliability analysis is now performed at each Gaussian integration point instead of using averaging techniques. In a previous version of C/CARES, ${ }^{1}$ element stresses were obtained by averaging the stress state at each node over the entire element. In finiteelement analysis, nodal stress data are usually computed by extrapolating the stresses from the integration .points; hence, the element stress tensor is approximate. This lack of accuracy becomes a difficulty in characterizing problems where high stress gradients exist over the element or where large element distortion occurs. As a result of the new subelement technique, the variation in stress over the element is taken into account, and considerable improvements in the accuracy of reliability analyses have been realized.

In addition to a new subelement technique, a modular program structure is introduced. Future changes and additions (e.g., implementation of more sophisticated failure models) are readily done without invoking large programming efforts. This version of C/CARES includes the option of using hybrid laminates, and it allows for variations in temperature fields throughout the component.
In this report, the $\mathrm{C} / \mathrm{CARES}$ interface for the finite-element package MARC is documented. In MARC, several shell elements (which utilize different shell theories) can be used to model the linear as well as nonlinear structural response of a thin-walled component to thermomechanical loads. Most of the data required for the reliability analysis are supplied by MARC, including the ply stress states and temperatures at the integration points. The ply stresses are provided in the local material coordinate system. Improvements of the MARC finite-element data interface and the new version of the C/CARES program are evident when a comparison is made of the reliability results to previous MSC/NASTRAN-C/CARES.

\section{$\underline{\text { Reliability Model }}$}

A great deal of work has been done to develop theories of the micromechanics of failure as they relate to ceramic matrix composites. $^{2,3}$ Application of these theories directly to structures of reasonable size is not practical because of the large number of localized failures and failure interactions which must be considered. For these reasons, the macroscopic phenomenological theories that have been advocated ${ }^{4-9}$ rely on homogenization of material properties. However, the required strength parameters are now taken to be random variables. The reliability functions most often used were borrowed from existing deterministic models. These reliability functions can be classified as either interactive, in which case the stresses are assumed to act in a collective fashion when causing failure, or noninteractive, in which case all stresses are still considered, but individually.

Noninteractive methods have the advantage of being evaluated in closed form and have been implemented in the past and current versions of C/CARES. Each unidirectional ply is considered independently and is allowed to possess five failure modes. (Delamination failure is not admitted in this approach.) In this model, the failure modes are characterized by tensile and compressive 
strengths in the fiber direction $\left(\sigma_{1}^{\mathrm{t}, \max }\right.$ and $\left.\sigma_{1}^{c, m a x}\right)$; tensile and compressive strengths in the direction transverse to the fiber $\left(\sigma_{2}^{t, m a x}\right.$ and $\left.\sigma_{2}^{c, m a x}\right)$; and in-plane shear strength $\left(\sigma_{12}^{\max }\right)$. These strengths are considered random variables that are characterized by three-parameter Weibull distribution functions. The reason for adopting this distribution is the anticipation that laminated CMC materials will exhibit threshold behavior, at least in the fiber direction. Inclusion of the threshold stress parameter allows for zero probability of failure when the load is below a predetermined level. The determination of these strengths requires a large number of experimental tests. In order to establish a reliable data base for CMC material systems, further experimental efforts are necessary.

To determine lower and upper reliability bounds, the weakest link theory (WLT, failure of the weakest link causes failure of the whole component) and the strongest link theory (SLT, failure of the whole component will not occur until every link has failed) are applied, respectively. In both approaches, the different failure modes are assumed to act independently. If WLT is assumed, the reliability of the $i^{\text {th }}$ ply can be expressed by

$$
\mathrm{R}_{\mathrm{i}}=\exp \left(-\int_{\mathrm{v}} \psi_{\mathrm{i}} \mathrm{dV}\right)
$$

where $\psi_{\mathrm{i}}$ is the risk of rupture intensity (per unit volume), and $\mathrm{V}$ is the ply volume.

The risk of rupture intensity $\psi_{i}$ is a function of position $x, y, z$ and of the local temperature $\mathrm{T}$ :

$$
\begin{aligned}
& \psi_{\mathrm{i}}(\mathrm{x}, \mathrm{y}, \mathrm{z}, \mathrm{T})=\left[\left(\frac{\left\langle\sigma_{1}-\gamma_{1}^{\mathrm{t}}(\mathrm{T})\right\rangle}{\beta_{1}^{t}(\mathrm{~T})}\right)^{\alpha_{1}^{\mathrm{t}}(\mathrm{T})}\right]_{\mathrm{i}} \\
& +\left[\left(\frac{\left\langle-\sigma_{1}+\gamma_{1}^{c}(T)\right\rangle}{\beta_{1}^{c}(\mathrm{~T})}\right)^{\alpha_{1}^{c}(\mathrm{~T})}\right]_{\mathrm{i}} \\
& +\left[\left(\frac{\left\langle\sigma_{2}-\gamma_{2}^{\mathrm{t}}(\mathrm{T})\right\rangle}{\beta_{2}^{\mathrm{t}}(\mathrm{T})}\right)^{\mathrm{t}(\mathrm{T})}\right]_{\mathrm{i}} \\
& +\left[\left(\frac{\left\langle-\sigma_{2}+\gamma_{2}^{\mathrm{c}}(\mathrm{T})\right\rangle}{\beta_{2}^{\mathrm{c}}(\mathrm{T})}\right)^{\alpha_{2}^{\mathrm{c}}(\mathrm{T})}\right]_{\mathrm{i}} \\
& +\left[\left(\frac{\left\langle\left|\sigma_{12}\right|-\gamma_{12}(\mathrm{~T})\right\rangle}{\beta_{12}(\mathrm{~T})}\right)^{\alpha_{12}(\mathrm{~T})}\right]_{\mathrm{i}}
\end{aligned}
$$

Note that $\gamma$ is the Weibull threshold parameter, $\alpha$ is the Weibull shape parameter, and $\beta$ is the Weibull scale parameter. In Eq. (2), these Weibull parameters are assumed to be temperature dependent. Superscript $t$ represents tensile, and superscript c denotes compressive conditions. Compressive stresses have a negative sign. In addition, $\sigma_{1}$ is the ply stress in the fiber direction, $\sigma_{2}$ is the ply stress transverse to the fiber direction, and $\sigma_{12}$ is the in-plane ply shear stress. The stresses are assumed to be constant over the ply thickness. Under the assumption of WLT, the component reliability is calculated by application of Eq. (1) to the whole component: 


$$
\mathrm{R}^{\mathrm{WLT}}=\prod_{\mathrm{i}=1}^{\text {nply }} \mathrm{R}_{\mathrm{i}}
$$

where nply is the number of plies in the laminate. Equation (3) represents a lower bound on the reliability. Thomas and Wetherhold ${ }^{7}$ proposed an upper-bound reliability limit estimate by assuming SLT, where

$$
\mathrm{R}^{\mathrm{SLT}}=1-\prod_{\mathrm{i}=1}^{\text {nply }}\left(1-\mathrm{R}_{\mathrm{i}}\right)
$$

\section{Program Features}

Since the stress field throughout a component is required for reliability analysis using the C/CARES algorithm, the structural response of the component to thermomechanical loads must be determined first (via the application of finite-element methods). Because of their relatively small thickness in comparison to the overall dimensions of the structure, components fabricated from laminated CMC material systems are conveniently modeled by using shell elements. In the formulation of typical shell elements, classical lamination theory is usually adopted to describe their mechanical behavior. The finite-element results have to be filtered since only ply stresses and ply temperatures at the integration points are required for the subsequent C/CARES reliability analysis. For convenience, the program is split into two parts: a finite-element data interface program and a reliability evaluation algorithm.

The finite-element data interface program interprets the data necessary for subsequent reliability analysis and translates the information into a formatted (ASCII) neutral data base. This concept enables easy data transfer between different computer systems. If the finite-element analysis and the reliability analysis are executed on the same computer system, the creation of an unformatted neutral data base is optional. In this case, faster and direct access to finite-element data is possible.

The reliability evaluation algorithm performs computations necessary for determining structural reliability. In the subelement technique, the risk of rupture intensity is evaluated at each Gaussian integration point instead of using averaging techniques. Stresses are exactly determined at the Gaussian integration points where the local stiffness matrix has already been evaluated. The subelement technique implies that each Gaussian integration point is referred to a subelement. The subelement volume is defined as the contribution of the integration point to the element volume in the numerical integration procedure. Thus, each ply in the laminate is divided into subelements, and the risk of rupture intensity function $\psi$ is evaluated for the corresponding stress tensor at the integration point. The number of subelements in each element depends on the order of integration chosen and on the element type. The increased number of points for stress evaluation accounts for the variation in stress over the element. Since the stress state is assumed to be constant over the subelement, the volume associated with a stress evaluation point substantially influences the reliability evaluation terms (see Eq. (1)). Due to the subdiscretization in the subelement method, even problems with high stress gradients or with distorted mesh geometries can be analyzed without remeshing the component (provided that the mesh density is sufficient to give accurate stresses).

The reliability analysis requires the stress state of each ply subelement, the ply subvolume, the local temperature, and the temperature-dependent Weibull parameters. Based on this information, the subelement reliability is expressed as

$$
\mathbf{R}_{i}^{\text {sub }}=\exp \left(-\psi_{i}^{\text {sub }} \mathbf{V}_{i}^{\text {sub }}\right)
$$

where $\psi_{\mathrm{i}}^{\text {sub }}$ is the value of the risk of rupture intensity within the subelement of the $i^{\text {th }}$ ply. 
Similarly, $V_{i}^{\text {sub }}$ is the volume of the subelement of the $i^{\text {th }}$ ply.

The value of the risk of rupture intensity $\psi_{i}^{\text {sub }}$ is determined by using Eq. (2). The Weibull parameters $\alpha, \beta$, and $\gamma$ are calculated with respect to the local temperature by linear interpolation of the material parameters specified in the control file.

The reliability of each ply is determined as the product of all subelement reliabilities within the model:

$$
\mathbf{R}_{\mathrm{i}}=\prod_{\mathbf{k}} \mathrm{R}_{\mathrm{i}}^{\mathrm{k}}=\exp \left[\sum_{\mathbf{k}}\left(\psi_{\mathrm{i}}^{\mathrm{sub}}\right)_{\mathrm{k}}\left(\mathrm{V}_{\mathrm{i}}^{\mathrm{sub}}\right)_{\mathrm{k}}\right]
$$

Thus, considerable improvements in the accuracy of reliability analyses have been realized (the reader is referred to the numerical examples that follow). After the reliability analysis is performed, the data for the risk of rupture intensity (a local measure of reliability) can be stored in a PATRAN element file. Thus, the design engineer is allowed to visualize critical regions in the structure by obtaining contour plots of the appropriate variables. The element risk of rupture intensity is approximated by averaging all subelements within the element and by using the following expression:

$$
\psi_{\mathrm{i}}^{\text {ele }}=\frac{\sum_{\mathrm{k}=1}^{\mathrm{nsub}} \psi_{\mathrm{i}}^{\mathrm{k}} \mathrm{v}_{\mathrm{i}}^{\mathrm{k}}}{\sum_{\mathrm{k}=1}^{\mathrm{nsub}} \mathrm{v}_{\mathrm{i}}^{\mathrm{k}}}
$$

where nsub is the number of subelements within one element $\left(\psi_{i}^{\text {ele }}\right.$ is only used for PATRAN postprocessing).

The current version of $\mathrm{C} / \mathrm{CARES}$ is programmed in standard FORTRAN 77 because it can be easily implemented on numerous computer systems from personal computers to mainframes. As a result of the subelement concept, a global structure of the algorithm has evolved. The introduction of one large, blank common array (instead of several fixed- dimension arrays) in each routine allows the user to easily adapt the program to the problem size and to the available computational resources. Since the program has been developed in a modular structure, future changes and additions (such as the introduction of more sophisticated reliability models) will not involve large programming efforts.

The program requires two input files, a control file, and a neutral data base. Defined in the control file are the number of different materials, the temperature-dependent Weibull parameters, the maximum number of plies, and flags for printing and postprocessing (e.g., writing the element risk of ruptures to a PATRAN element file). The neutral data base is discussed in the next section.

\section{$\underline{\text { Neutral Data Base Concept }}$}

The formatted neutral data base allows C/CARES to be interfaced with several finiteelement programs. At the present time the interface program to MARC has been implemented. Interfaces to MSC/NASTRAN and ABAQUS are being prepared.

The structure of the neutral data base is optimized with respect to memory. The finite-element data are arranged within the neutral data base by using the following hierarchy: element groups, elements, and subelements. Element groups are already defined in the finite-element analysis. Elements with the same laminate structure are combined into one group. If reliability analysis is focused on a special part of a component (e.g., a region with stress concentrations), the corresponding elements can be combined into an element group. The element group data contain information regarding the number of elements within the group. Information pertaining to the elements includes the number of subelements (integration points) and the number of plies associated with each element. Finally, the subelement data contain information regarding ply identification, ply subvolume, ply stress state (assuming plane stress conditions), ply temperature, and ply material 
type. Note that a subelement can have more than one ply.

Typically, ply volumes are not included with standard finite-element output. Thus, the volume of each subelement (corresponding to a Gaussian integration point) is calculated by using the shape functions inherent to the element type. Currently, bilinear (four nodes) and biquadratic (eight nodes) element shape functions are utilized to determine the subelement volumes. The subelement volumes are computed by using the following expression:

$$
\mathrm{V}_{\text {ply,sub }}=\mathbf{A}_{\text {ply,sub }} \mathrm{t}_{\text {ply }}
$$

where $A_{\text {ply,sub }}$ is the midsurface area of the shell subelement (corresponding to the integration point considered), and $t_{\text {ply }}$ is the ply thickness.

The midsurface area of a shell element is calculated by integration in natural space (see Bathe $^{10}$ for details):

$$
A=\int_{-1}^{1} \int_{-1}^{1} \operatorname{det} J(r, s) d r d s
$$

where $\mathbf{J}$ is the Jacobian operator, and $r, s$ are natural coordinates.

By applying a Gaussian integration scheme, this integral can be expressed as

$$
A=\sum_{i=1}^{m} \sum_{j=1}^{m} \operatorname{det} J\left(r_{i}, s_{j}\right) W_{i} W_{j}
$$

where $m$ is the integration order, $r_{i}, s_{j}$ are the coordinates of the Gaussian integration points in natural space, and the W's are weight functions.

The Jacobian operator $\mathbf{J}$ is calculated by using the corresponding element shape functions, element connectivities, and global coor- dinates of the element nodes. The subelement area corresponding to the integration point $\mathbf{r}_{i}, \mathbf{s}_{\mathbf{j}}$ represents one summation term in Eq. (10).

\section{Numerical Examples}

To illustrate the improvements achieved by the updated version of C/CARES (coupled to the MARC finite-element program), results of a benchmark problem reliability analysis are compared to the previously completed analysis for the same problem where C/CARES was coupled to MSC/

NASTRAN. ${ }^{11}$ Specifically, a laminated CMC plate with a central circular hole was subjected to prescribed edge displacements at room temperature (see Fig. 1). The elastic material properties are presented in Table 1. The laminate consists of eight unidirectional orthotropic plies with a $[0 / \pm 45 / 90]_{s}$ ply layup. Note that, because experimental data are lacking, assumed values for $\alpha, \beta$, and $\gamma$ (which are temperature dependent) were used. In order to model this quasi-two-dimensional problem, appropriate degrees of freedom are retained in each analysis.

Two mesh densities were used for the finite-element analysis of this problem. The first mesh contained 2520 elements; the second coarser mesh contained 1000 elements. A two-by-two integration scheme was used for both MARC analyses (four subelements for each shell element). The finite-element results were transformed into a neutral data base, and the reliability analysis was performed with the Weibull strength parameters given in Table 2. In Table 3, the component reliabilities $\mathrm{R}^{\mathrm{WLT}}$ are given for both MARC-C/ CARES analyses and the original MSC/NASTRAN-C/CARES analyses. The component reliability based on SLT is nearly unity, since the high reliabilities $R_{i}$ for plies 2 to 7 dominate the calculation of $R^{S L T}$. In Table 4 the reliability $R_{i}$ for each ply from the MARC analysis (dense mesh) is compared to the ply reliabilities from the MSC/NASTRAN analysis. 
The plies with a fiber orientation of $0^{\circ}$ (plies 1 and 8) are subject to the highest stresses in the laminate. Consequently, these plies are the least reliable (see Table 4). In Figs. 2 and 3, the risk of rupture intensity $\psi_{i}^{\text {ele }}$ is depicted in the vicinity of the hole for ply 1 (fiber orientation $0^{\circ}$ ) and for ply 2 (fiber orientation $+45^{\circ}$ ), respectively.

Because the risk of rupture intensity is directly dependent on the stress state, the stress concentration is clearly evident.

The reliability analyses using MARC results yielded smaller component reliabilities for both the coarse and the fine mesh relative to the MSC/NASTRAN analyses. The decrease in reliability is a consequence of the more accurate reliability computations in the region of the stress gradient. Both MARC analyses yielded close values for the maximum stress in the fiber direction (within 1.6 percent); the value of $\sigma_{1}^{\max , c}$ is $433.8 \mathrm{MPa}$ for the coarse mesh, and the value of $\sigma_{1}^{\max , \mathrm{d}}$ is 440.8 MPa for the dense mesh. The maximum stress in the fiber direction determined with MSC/NASTRAN, however, is smaller: the value of $\sigma_{1}^{\max , c}$ is $416.0 \mathrm{MPa}$ (coarse mesh), and the value of $\sigma_{1}^{\max , d}$ is $423.0 \mathrm{MPa}$ (dense mesh). These results may be attributed to the averaging method used in MSC/NASTRAN to determine the centroidal stress for each element. Thus, the stress gradient in the component could only be approximated. Stresses at the maximum stress location may be underestimated for the MSC/ NASTRAN analysis, resulting in a higher component reliability for this problem. The MARC results show that the mesh density is sufficiently fine, even for the coarse mesh, to determine stresses accurately at the integration points. This ability to model a structural component with a coarse mesh by using subelements represents a considerable reduction of computational effort in component design.

\section{Conclusion}

Based on the previous version of C/CARES, an enhanced version of this inte- grated design program was developed for the reliability evaluation of ceramic matrix composite (CMC) laminated shell components. By dividing the original program into two separate modules, more flexibility is achieved, allowing for easy implementation with various finite-element programs. As a result of the introduction of a shell subelement technique, the number of reliability function evaluation points is increased. A numerical example has demonstrated improvements in the accuracy of reliability analyses. In order to achieve the same order of accuracy, the new version allows structural components to be modeled with coarser finite-element meshes than those required by the previous version of the program. The modular structure of the program allows the design engineer to incorporate additional reliability functions without major programming efforts. Future versions of $\mathrm{C}$ /CARES will focus on this issue.

\section{$\underline{\text { References }}$}

1. Duffy, S.F., Palko, J.L., and Gyekenyesi, J.P., "Structural Reliability Analysis of Laminated CMC Components," NASA TM-103685, 1991.

2. Budiansky, B., Hutchinson, J.W., and Evans, A.G., "Matrix Fracture in Fiber-Reinforced Ceramics," Journal of the Mechanics and Physics of Solids, Vol. 34, No. 2, 1986, pp. 167-189.

3. Marshall, D.B., Cox, B.N., and Evans, A.G., "The Mechanics of Matrix Cracking in Brittle-Matrix Fiber-Reinforced Composites," Acta Metallurgica, Vol. 33, No. 11, 1985, pp. 2013-2021.

4. Duffy, S.F., and Arnold, S.M., "Noninteractive Macroscopic Reliability Model for Whisker-Reinforced Ceramic Composites," Journal of Composite Materials, Vol. 24, No. 3, 1990, pp. 293-308. 
5. Duffy, S.F., and Manderscheid, J.M., "Noninteractive Macroscopic Reliability Model for Ceramic Matrix Composites with Orthotropic Material Symmetry," Journal of Engineering for Gas Turbines and Power, Vol. 112, No. 4, 1990, pp. 507-511.

6. Hu, T.G., and Goetschel, D.B., "The Application of the Weibull Strength Theory to Advanced Composite Materials," Tomorrow's Materials: Today, Proceedings of the 34th International SAMPE Symposium and Exhibition, G.A. Zakrzewski et al., eds., SAMPE, Covina, CA, Vol. 1, 1989, pp. 585-599.

7. Thomas, D.J., and Wetherhold, R.B., "Reliability Analysis of Continuous Fiber Composite Laminates," Composite Structures, Vol. 17, No. 4, 1991, pp. 277-293.
8. Wetherhold, R.C., and Pipes, R.B., "Statistics of Fracture of Composite Materials Under Multiaxial Loading," Journal of Materials Science Engineering, Vol. 68, Dec. 1984, pp. 113-118.

9. Wu, H.F., "Statistical Analysis of Tensile Strength of ARALL Laminates," Journal of Composite Materials, Vol. 23, No. 10, 1989, pp. 1065-1080.

10. Bathe, K.J., Finite Element Procedures in Engineering Analysis. Prentice-Hall, Englewood Cliffs, NJ, 1982.

11. Palko, J.L., "Reliability Analysis of a Laminated Composite Plate with a Central Hole," Presented at the 36th International Gas Turbine and Aeroengine Congress and Exposition, Orlando, FL, June 3-6, 1991.

TABLE 1.-ELASTIC PROPERTIES

Young's modulus in fiber direction, $\mathrm{E}_{1}, \mathrm{MPa} \ldots \ldots \ldots \ldots \ldots \ldots$

Young's modulus transverse to fiber direction, $\mathrm{E}_{2}, \mathrm{MPa} \ldots \ldots \ldots \ldots \ldots$

Shear modulus, $\mathbf{G}_{1}, \mathbf{G}_{13}, \mathbf{G}_{23}, \mathbf{M P a} \ldots \ldots \ldots \ldots \ldots$

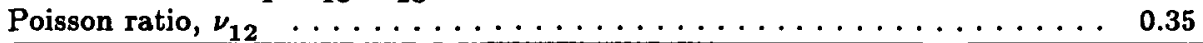

TABLE 2.-WEIBULL STRENGTH PARAMETERS

\begin{tabular}{|l|c|c|c|}
\hline \multirow{2}{*}{ Failure mode } & \multicolumn{3}{|c|}{ Weibull strength parameter } \\
\cline { 2 - 4 } & Shape, & Scale, \\
$\alpha$, & Threshold, \\
& $\alpha$, & $\mathrm{MPa}^{2}$ \\
\hline & & & \\
\hline Fiber direction & 25 & 450 & 0 \\
Tensile, $\sigma_{1}^{\mathrm{t}, \max }$ & 35 & 4500 & \\
Compressive, $\sigma_{1}^{\mathrm{c}, \max }$ & & & \\
Transverse to fiber direction & 10 & 350 & \\
Tensile, $\sigma_{1}^{\mathrm{t}, \max }$ & 30 & 3500 & \\
Compressive, $\sigma_{1}^{\mathrm{c}, \max }$ & 22 & 420 & \\
In-plane shear, $\sigma_{12}^{\max }$ & & \\
\hline
\end{tabular}


TABLE 3.-COMPARISON OF DIFFERENT RELIABILITY ANALYSES

\begin{tabular}{|l|c|c|}
\hline \multicolumn{1}{|c|}{ Analysis } & $\begin{array}{c}\text { Number of } \\
\text { elements }\end{array}$ & $\begin{array}{c}\text { Component } \\
\text { reliability, } \\
\mathbf{R}^{\text {WK T }}\end{array}$ \\
\hline MARC & 1000 & 0.9005 \\
MSC/NASTRAN & 1000 & .9304 \\
MARC & 2520 & .8959 \\
MSC/NASTRAN & 2520 & .9328 \\
\hline
\end{tabular}

TABLE 4.-PLY-BY-PLY RELIABILITY RESULTS

\begin{tabular}{|c|r|c|c|}
\hline \multirow{2}{*}{$\begin{array}{c}\text { Ply } \\
\text { number }\end{array}$} & \multirow{2}{*}{$\begin{array}{c}\text { Fiber } \\
\text { angle, } \\
\text { deg }\end{array}$} & \multicolumn{2}{|c|}{$\begin{array}{c}\text { Ply reliability, } \\
\text { 2520 elements }\end{array}$} \\
\cline { 3 - 4 } & & $\begin{array}{c}\text { MSC/NASTRAN - } \\
\text { previous C/CARES }\end{array}$ & $\begin{array}{c}\text { MARC - } \\
\text { new C/CARES }\end{array}$ \\
\hline 1 & 0 & 0.96587 & 0.94652 \\
2 & +45 & .99999 & .99999 \\
3 & -45 & & \\
4 & +90 & & \\
5 & +90 & & \\
6 & -45 & &. \\
7 & +45 &. & .94652 \\
8 & 0 & .96587 & \\
\hline
\end{tabular}

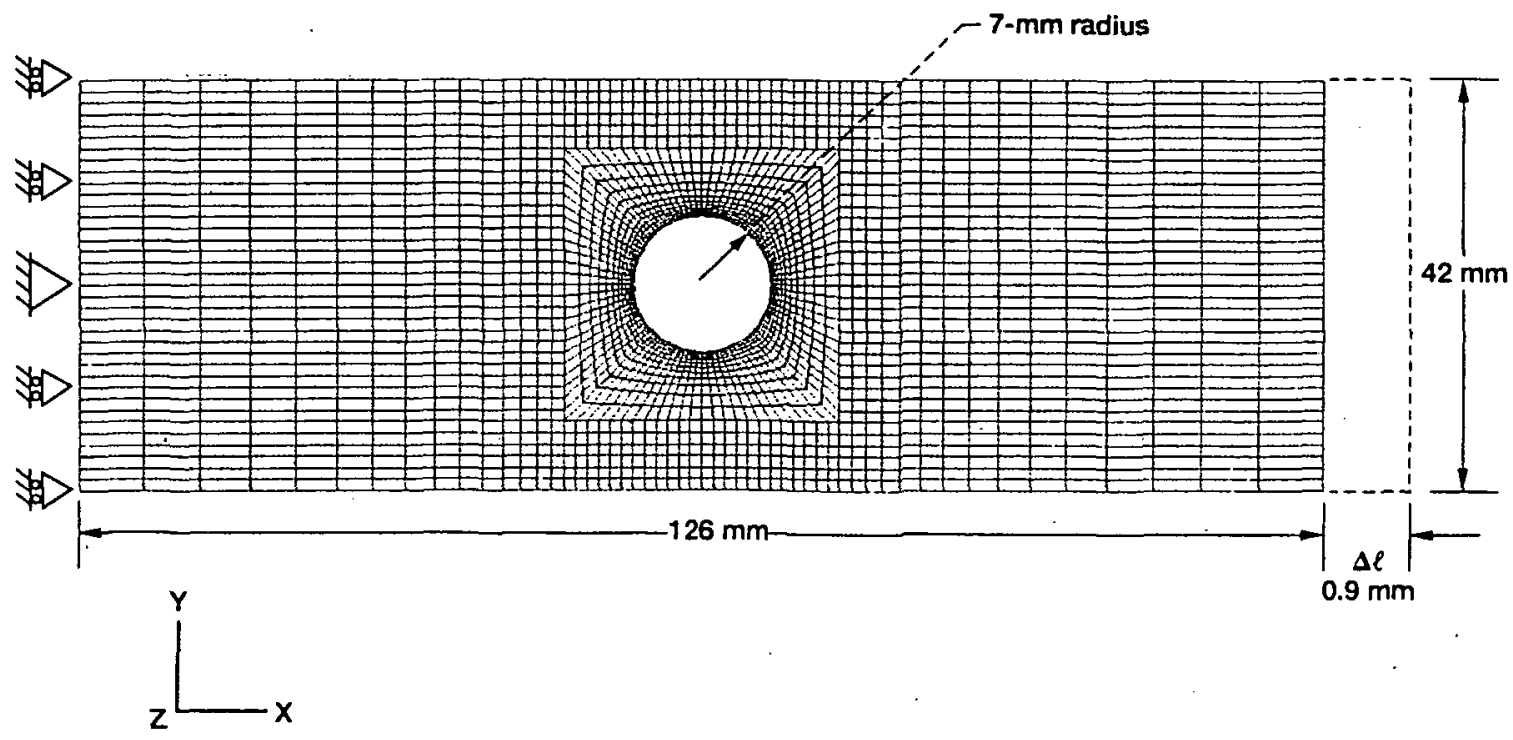

Figure 1. Finite-element mesh for $[0 / \pm 45 / 90]_{\mathrm{s}}$ laminate. Ply thickness t, $0.2 \mathrm{~mm}$. 


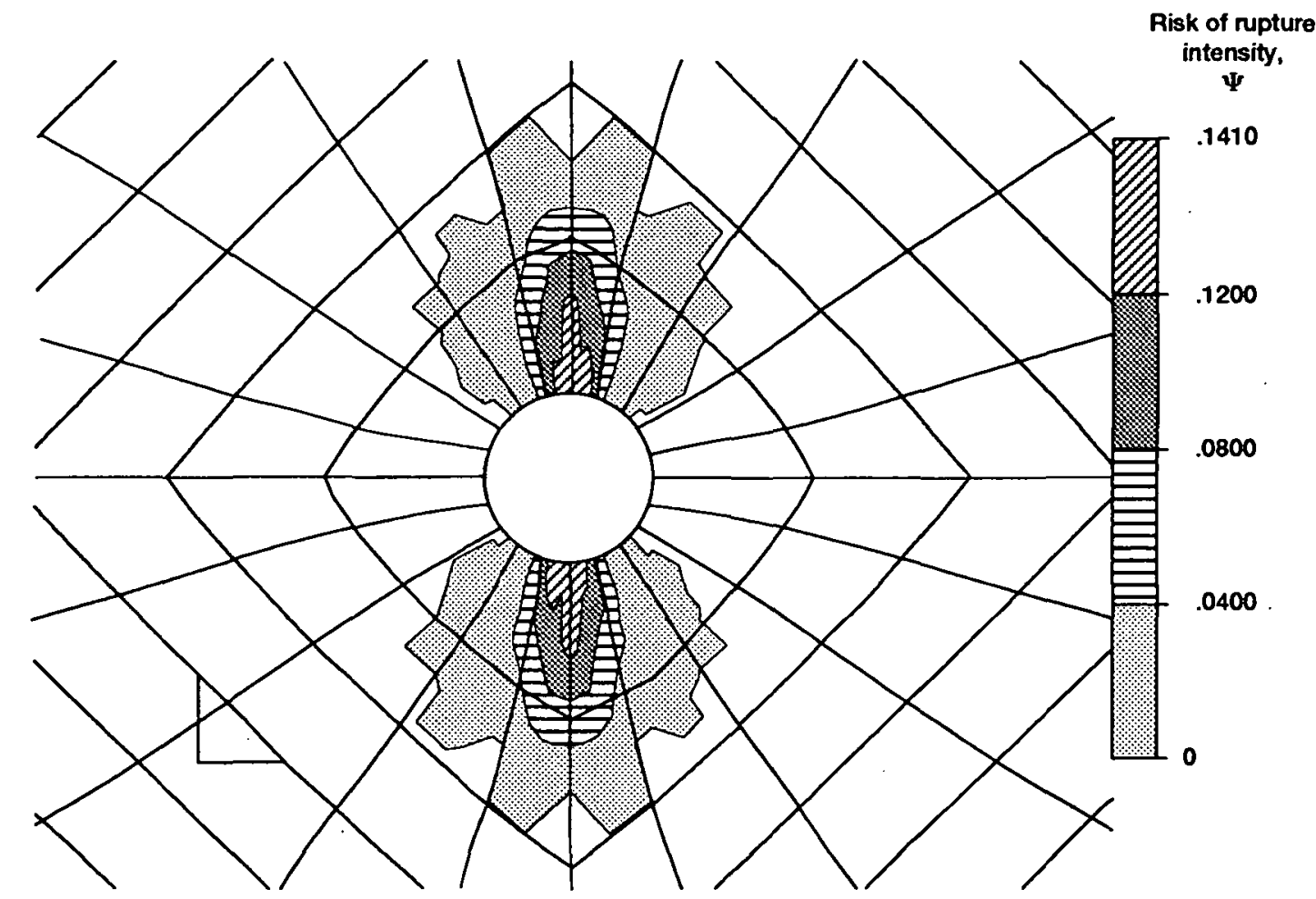

Figure 2-Risk of rupture intensity $\Psi$ around the hole for ply number 1 ( $0^{\circ}$ fiber orientation).

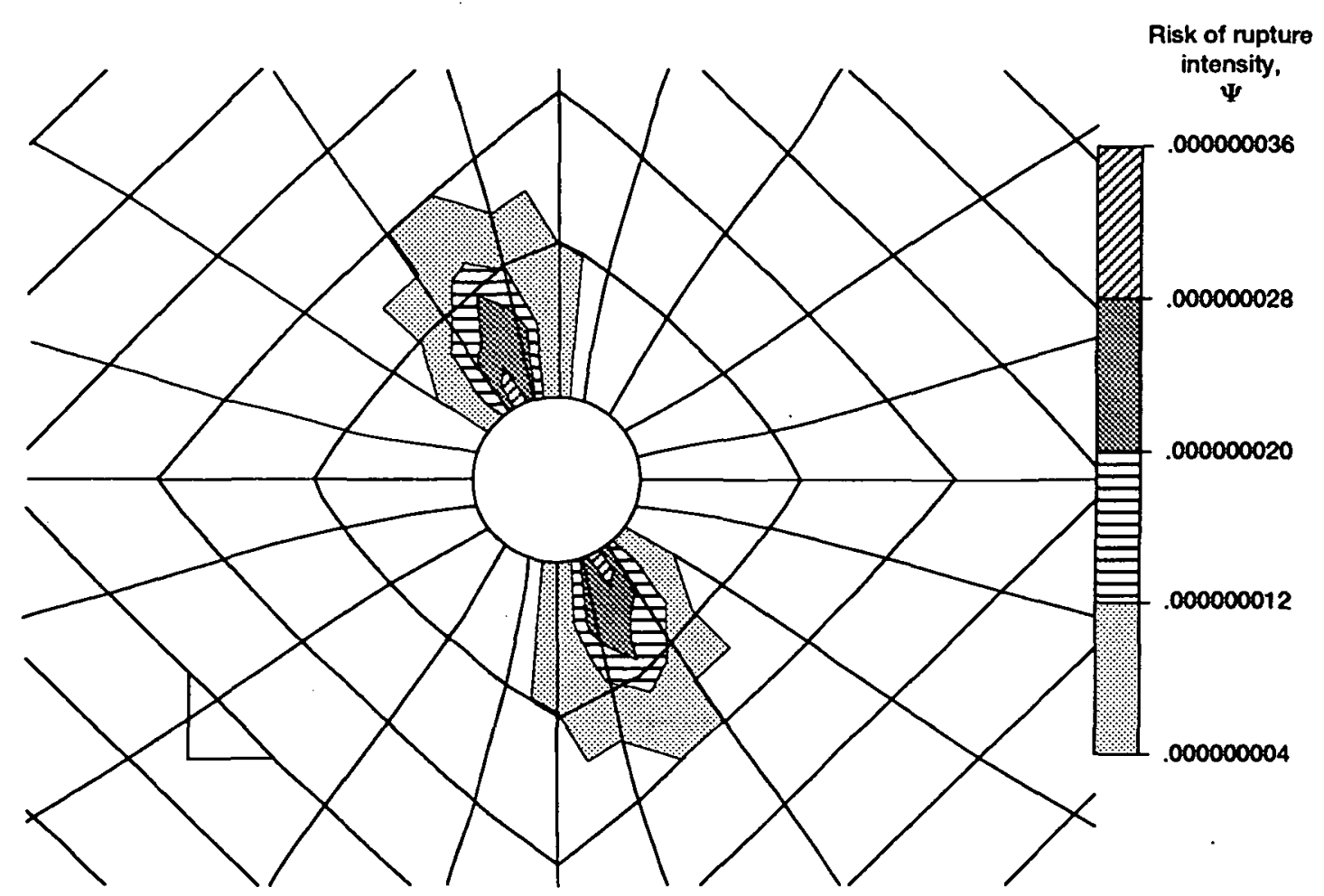

Figure 3.-Fisk of rupture intensity $\Psi$ around the hole for ply number $2\left(+45^{\circ}\right.$ fiber orientation). 
Public reporting burden for this collection of information is estimated to average 1 hour per response, including the time for reviewing instructions, searching existing data sources, gathering and maintaining the data needed, and completing and reviewing the collection of information. Send comments regarding this burden estimate or any other aspect of this collection of information, induding suggestions for reducing this burden, to Washington Headquarters Services, Directorate for information Operations and Reports, 1215 Jefferson Davis Highway, Suite 1204, Arlington, VA 22202-4302, and to the Office of Management and Budget, Papenwork Reduction Project (0704-0188), Washington, DC 20503.

\begin{tabular}{|l|c|c|}
\hline 1. AGENCY USE ONLY (Leave blank) & $\begin{array}{r}\text { 2. REPORT DATE } \\
1992\end{array}$ & $\begin{array}{r}\text { 3. REPORT TYPE AND DATES COVERED } \\
\text { Technical Memorandum }\end{array}$ \\
\hline TITLE AND SUE
\end{tabular}

\section{TITLE AND SUBTITLE}

5. FUNDING NUMBERS

Reliability Analysis of Laminated CMC Components

Through Shell Subelement Techniques

\section{AUTHOR(S)}

WU $-505-63-5 B$

Alois Starlinger, Stephen F. Duffy, and John P. Gyekenyesi

7. PERFORMING ORGANIZATION NAME(S) AND ADDRESS(ES)

8. PERFORMING ORGANIZATION REPORT NUMBER

National Aeronautics and Space Administration

Lewis Research Center

Cleveland, Ohio 44135-3191

$E-6819$

9. SPONSORING/MONITORING AGENCY NAMES(S) AND ADDRESS(ES)

10. SPONSORING/MONITORING AGENCY REPORT NUMBER

National Aeronautics and Space Administration Washington, D.C. 20546-0001

NASA TM- 105413

AIAA-92-2348

11. SUPPLEMENTARY NOTES

Prepared for the 33rd Structures, Structural Dynamics and Materials Conference sponsored by the American Institute of Aeronautics and Astronautics, Dallas, Texas, April 13-15, 1992. Alois Starlinger, National Research Council-NASA Research Associate at Lewis Research Center. Stephen F. Duffy, Cleveland State University, Department of Civil Engineering, Cleveland, Ohio 44115 and NASA Resident Research Associate at Lewis Research Center. John P. Gyekenyesi, NASA Lewis Research Center. Responsible person, Alois Starlinger, (216) 433-6510.

\begin{tabular}{l|l} 
12a. DISTRIBUTION/AVALABILITY STATEMENT & 12b. DISTRIBUTION CODE
\end{tabular}

Unclassified - Unlimited

Subject Category 27

\section{ABSTRACT (Maximum 200 words)}

An updated version of the integrated design program C/CARES (composite ceramics analysis and reliability evaluation of structures) was developed for the reliability evaluation of CMC laminated shell components. The algorithm is now split into two modules: a finite-element data interface program and a reliability evaluation algorithm. More flexibility is achieved, allowing for easy implementation with various finite-element programs. The interface program creates a neutral data base which is then read by the reliability module. This neutral data base concept allows easy data transfer between different computer systems. The new interface program from the finite-element code MARC also includes the option of using hybrid laminates (a combination of plies of different materials or different layups) and allows for variations in temperature fields throughout the component. In the current version of C/CARES, a subelement technique was implemented, enabling stress gradients within an element to be taken into account. The noninteractive reliability function is now evaluated at each Gaussian integration point instead of using averaging techniques. As a result of the increased number of stress evaluation points, considerable improvements in the accuracy of reliability analyses have been realized.

14. SUBJECT TERMS

Ceramic design; Ceramic matrix composites; Reliability; C/CARES; Weakest link theory; Weibull; Finite element analysis; MARC; Composite failure

17. SECURITY CLASSIFICATION OF REPORT

Unclassified
18. SECURITY CLASSIFICATION OF THIS PAGE

Unclassified
19. SECURTYY CLASSIFICATION OF ABSTRACT Unclassified
15. NUMBER OF PAGES 12 16. PRICE CODE $\mathrm{A03}$

20. LIMITATION OF ABSTRACT 
National Aeronautics and

Space Administration

Lewis Research Center

Cleveland, Ohio 44135

Official Business

Penalty for Private Use $\mathbf{\$ 3 0 0}$

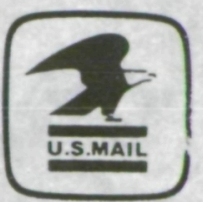

Postage and Fees Paid National Aeronautics and

Space Administration

NASA 451 